\title{
Food Preference Predicts Speed of Approach on a Runway Task by Dogs
}

\author{
Kristie E. Cameron ${ }^{1 *}$, Jane de Garnham ${ }^{1}$, Kristeen Jensen ${ }^{1} \&$ Lewis A. Bizo ${ }^{2}$
}

\section{Abstract}

The effective and quick assessment of food preference is important when attempting to identify foods that might function as effective reinforcers in dogs. In the current experiment, more highly preferred foods were expected to be associated with faster approaches in a subsequent runway task. Eight dogs experienced combinations of two of six types of raw food in a paired preference assessment. These included the dog's staple diet, to identify a rank order of preference for the foods. A different raw food was offered as the staple in two preference tests. In the runway task, the dogs were required to walk five metres to obtain a small amount of their most preferred, least preferred or staple foods and latency of approach to the foods was recorded. The results showed that the staple foods were not preferred as highly as the other foods and that each dog displayed unique and stable preferences for the different foods. The approach latencies were faster for their most-preferred food compared to their least preferred and the staple foods. The use of a runway to assess reinforcer effectiveness combined an effortful behaviour to obtain food while also requiring the dogs to make a choice, thus precluding the need for more complicated and time-consuming methods of preference assessment. The application of this method for fast and effective identification of preferred reinforcers is currently being investigating further to inform pet owners and behavioural scientists better about simple methods that they might use to identify highly preferred foods for use as reinforcers in training and behavioural testing.

Pet Behaviour Science | 2019, Vol.8, 1-10

DOI: $10.21071 /$ pbs.v0i8.11179

Kristie E. Cameron, Jane de Garnham, Kristeen Jensen \& Lewis A. Bizo

1 Unitec Institute of Technology, $\quad$ Research paper

Auckland, New Zealand

* Environmental and Animal

Sciences Pathway

Unitec - Institute of Technology

Carrington Road, Auckland

New Zealand

Tel: +64 98154321 ext 8578

2 University of New England, Armidale, Australia
*Email: kcameron@unitec.ac.nz

Keywords:

Dog, Food Preference,

Reinforcer Assessment, Raw

Food, Response Latency;

Runway

\section{Highlights}

- High-value foods are reported to function as more effective reinforcers than low-value foods.

- Dogs do not value staple foods highly.

- Dogs move faster in a runway ask for highly preferred foods compared to staple or lowly preferred foods.

- Dog owners are encouraged to conduct preference assessments to identify their dog's most preferred food for use as a reinforcer during training. 


\section{INTRODUCTION}

To promote the welfare of domestic pets, it is important that pet owners employ positive training techniques. An example of a positive training technique is the delivery of a reward that is contingent on an animal producing the appropriate behaviour. Delivery of a reward should increase the likelihood an animal will repeat that behaviour in the future (e.g., Hiby, Rooney and Bradshaw 2004; Haverbeke, Laporte, Depiereux, Giffroy and Diederich 2008;); a technique used in behavioural science where the occurrence of behaviour is measured in relation to the delivery of reinforcement, usually food, according to a schedule of reinforcement. In addition, rewarding desired behaviour is reported to strengthen the human-animal bond (Deldalle and Gaunet 2014; Payne, Bennett and McGreevy 2015), decrease animal stress during training (Deldalle and Gaunet 2014) and mitigate the development of problematic behaviour which can result in relinquishment of the dog by the owner if it persists (Blackwell, Twells, Seawright and Casey 2008). To successfully implement positive reinforcement, one must use a functional reinforcer; this means that the reinforcer is highly valued by the animal (Gaalema, Perdue and Kelling 2011; Vicars, Miguel and Sobie 2014).

Conducting systematic preference assessments in humans is a method of identifying food and leisure items to reward desired behaviour (DeLeon and Iwata 1996; Fisher et al. 1992). More recently the same technology has been used by animal keepers to provide preferred food and enrichment to animals such as with: Horses (Equus caballus; Elia, Erb and Houpt 2010); Orangutans (Pongo spp.; Clay, Bloomsmith, Marr and Maple 2009); Cats (Felis silvestris catus; Vitale Shreve, Mehrkam and Udell 2017); Giant Pandas (Ailuropoda melanoleuca) and African Elephants (Loxodonta Africana; Gaalema et al. 2011), all of which found idiosyncratic differences between individuals of each species. Behavioural scientists also use these tests to identify preferred foods to supply as reinforcers in operant experiments with various animals including brushtail possums (Trichosurus vulpecula; Cameron, Bizo and Starkey 2013) and hens (Gallus gallus; Sumpter, Foster and Temple 2002) and to examine preferred or aversive environmental components such as ammonia concentration by sheep (Ovis aries; Phillips, Pines and Muller 2012). One particular instance where this is particularly important is when animals are on a restricted diet such as in a laboratory environment where the motivation to perform for food is often a critical component of the experimental method (Cameron, Bizo and Starkey 2015) or a veterinarian has suggested a specialised diet.

There are populations of pet dogs that are fed raw food diets for various reasons (Ackerman 2016). Given these dogs are unable to consume commercial treats, it is necessary to be able to identify foods they can eat, that will be highly valued, and that would function as a reward in dog training and operant experiments to motivate and reinforce the occurrence of target behaviour for this population. For this experiment, raw food fed dogs were chosen as subjects for this study because it is recommended by commercial sellers of raw food that dogs should not eat store-bought treats or high-value human food as it decreases their gut-acidity and results in the dog having digestive issues and gastrointestinal upset (Thompson 2016). Instead, owners have reported using a particular 'flavour' of their dogs staple raw food such as rabbit, horse or veal mixed with tripe in packets sold by retailers as a reinforcer or reward for their dog. It is unclear, however, given these dogs are restricted to raw food, whether using a dog's normal diet would be as effective as a reinforcer during training as other novel foods. It is reported in numerous studies that a staple food, such as 'dry dog biscuit' is commonly of lower preference than other types of food such as sausage, cheese or 'treats' as indicated in preference and reinforcer assessments with dogs (e.g., Thompson, Riemer, Ellis and Burman 2016; Riemer, Ellis, Thompson and Burman 2018). Others have identified a 'novelty' or 'monotony effect' in preference tests with dogs and cats where novel foods are preferred over a long-term staple diet (e.g., Ferrell 1984; Bradshaw 2006; Vondran 2013). There is; however, a report of puppies preferring the diet on which they were weaned over a diet of novel foods (Ferrell 1984).

A well-researched method used for assessing preference with animals is the paired stimulus preference assessment (e.g., Cameron et al. 2013; Clay et al. 2009) as it requires little effort on the part of the 
researcher, does not involve large amounts of food and is relatively quick to administer (Vicars et al. 2014; Riemer et al. 2018;). It is also a valid and reliable method for assessing preference and involves pairs of food or items being systematically offered to the subject with their choice recorded (Fisher et al. 1992) and is reliable over time (e.g., Cameron et al. 2013).

The use of operant manipulanda, where an animal can respond on a lever or a response key so that they can either work for or indicate a choice of a particular commodity is not a new technology. Collier, Hirsch and Hamlin (1972) required rats to respond on increasing fixed ratio schedules to earn their entire food ration. This closed economy resulted in consistently high numbers of responses. The requirement to earn one's food is clearly a great motivator. Responding to simple schedules of reinforcement has been used to measure the value of reinforcers to an organism in single (e.g., Bizo and Killeen 1997; Jarmolowicz and Lattal 2010) and concurrent arrangements (e.g., Sumpter et al. 2002) and the demand for commodities by requiring them to commit physical effort to obtain a particular item (e.g., Hursh, Madden, Spiga, DeLeon and Francisco 2013). Tests designed to measure the effort put forth to gain a commodity have been conducted in a variety of animals such as possums (Cameron et al. 2015; Cameron, Clarke, Bizo and Starkey 2016), horses (Elia et al. 2010) and dogs (Vicars et al. 2014). Previous studies have reported that foods of low preference, including staple foods, produced lower rates of responding compared to foods of high value, for example to those with a higher sugar content, such as berries for possums (Cameron et al. 2015) and high protein or fat coated treats for dogs (e.g., Rashotte, Foster and Austin 1984; Hewson-Hughes et al. 2012).

More recently, researchers have investigated methods of measuring captive animal's 'demand' for commodities such as particular foods by pressing levers in possums (Cameron et al. 2015; Cameron et al. 2016), pressing keys in hens (e.g., Foster, Sumpter, Temple, Flevill and Poling 2009), using a touch response (Vicars et al. 2014) or runway movement for two particular commodities in dogs (Riemer et al. 2018; Thompson et al. 2016). A 'work' requirement has also been used to measure demand for a variety of commodities such as substrate in pigs (e.g., Holm,
Jensen, Pedersen and Ladewig 2008) and hens (e.g., de Jong, Wolthuis-Fillerup and van Reenen 2007), and enclosure enrichment in various species kept in captivity such as lizards (e.g., Januszczak et al. 2016), and rabbits (e.g., Seaman, Waran, Mason and D'Eath 2008). An animal indicating a need for a particular event or commodity, by committing physical effort in responding to obtain it, suggests that it should be provided to maintain the wellbeing of the animal (Dawkins 1988; 2004). The same logic should hold for selecting a functional reinforcer for successful training; if an animal commits physical effort to obtain one type of food over another, it should be used as a reinforcer for training to be effective.

Preference and reinforcer assessments have been conducted with dogs to measure the palatability of commercially available dog food where dogs display a tendency to choose a novel food option over their staple diet (e.g., Vondran 2013). Dogs have also been observed to forego a low-value food or a small quantity of food for a high-value or larger amount of food (Leonardi, Vick and Dufour 2012), indicating an ability to discriminate between larger and smaller amounts of food (e.g., McGuire, Bizo, McBride and Kocek, 2018). Dogs showed a preference for dried meat, cheese or treat-type foods over mundane dog food and biscuits. The dogs did not respond for the low-value food but responded to higher response requirements and for longer to obtain the most-preferred food type when the dogs were required to perform a nose-touch response to a fixed object to obtain the most- or least-preferred food in a reinforcer assessment task (Vicars et al. 2014). Dogs reinforced with a high-value liver treat held the experimenter's gaze for a longer duration than dogs either trained using dog pellets or those that had been reinforced previously with the high-value treat (Bentosela, Jakovcevic, Elgier, Mustaca and Papini 2009).

Similarly, dogs spend more time interacting with an inaccessible high-value meat reinforcer than dry food in tests where the food was covered with a wire-netting cover (Thompson et al. 2016). When dogs are exposed to choice tests of foods of differing qualities and quantities they tended to select the larger amount and more highly valued foods more often (Riemer et al. 2018). The authors concluded that a more highly valued 
food is likely to be a more effective reinforcer, and that is not likely to include staple food.

The current study aimed to assess the appropriateness and practicality of a preference assessment method using a combined effortful and choice procedure to assess preferences in dogs. This involved identifying a rank order of preference for six flavours of raw food using a paired stimulus preference assessment and then assess if that rank order predicted rates of responding for those foods on a simple schedule of reinforcement. The reinforcer assessment required dogs to walk down a 5-m runway to obtain their staple, most- or least-preferred foods. We predicted that dogs would approach their most-preferred food faster compared to a staple or least-preferred food.

\section{METHOD}

\section{Subjects}

Eight domestic dogs of various breeds participated in the experiment (Table 1), and owners gave their permission before testing. The University of Auckland Ethics committee approved this research (approval number 001769).

Table 1. Subject information; name, sex, breed and life stage of each dog. 'Food' represents the amount of food offered per trial

\begin{tabular}{cccc}
\hline Name (Sex) & Breed & Life stage & Food (g) \\
\hline Bradley (M) & $\begin{array}{c}\text { Australian } \\
\text { Shepard } \\
\text { Alaskan } \\
\text { Miika (F) }\end{array}$ & Adult & 5 \\
malamute & Adult & 5 \\
Indy (F) & $\begin{array}{c}\text { Rhodesian } \\
\text { Ridgeback X }\end{array}$ & Adult & 5 \\
Moe (M) & $\begin{array}{c}\text { Mixed Breed } \\
\text { Morder Collie }\end{array}$ & $\begin{array}{c}\text { Young } \\
\text { Adult }\end{array}$ & 5 \\
Poppy (F) & $\begin{array}{c}\text { Miniature } \\
\text { Schnauzer } \\
\text { Maltese Shih } \\
\text { Tzu }\end{array}$ & Adult & 3 \\
Rex (M) & $\begin{array}{c}\text { Adult } \\
\text { Runty (F) }\end{array}$ & $\begin{array}{c}\text { Terrier X } \\
\text { German } \\
\text { Shepard }\end{array}$ & Young \\
Skye (F) & Adult & 3 \\
\hline
\end{tabular}
loose lead in a 'sit' position at the beginning of the route. The owner would instruct the dog to move and then walk behind the dog to avoid developing an owner-induced side bias to the food samples. Initially,

Trials were conducted indoors in the dog's home or in a private room at the local doggy-daycare facility where the dog was familiar. A 'virtual runway' was created with a straight space approximately $2-3 \mathrm{~m}$ long where two plates with a food sample on each marked the end of the runway.

Before the first paired-stimulus preference assessment, owners were instructed to feed their dog their normal ration of a specific raw food type for each meal for the three days before testing. Dogs were offered different food types of the same branded raw food made from a "natural, preservative free, species-appropriate raw food diet" (Gourmet PetFood Kitchen Limited, 2015). Before the first test, the dogs received 'rabbit,' and before the second test conducted two weeks later, they received 'horse.' The other foods offered were chicken, tripe, duck and lamb.

To calculate the amount of food offered each dog would receive in a trial, the dog's normal morning ration of food was divided by the number of trials conducted in a session (approximately 36). A food sample of this amount of food type was then offered to the dog on each trial during the assessment (see Table 1 for the amount of food each dog received).

\section{Procedure}

The paired preference assessment consisted of 30 trials where food presentation was counter-balanced across sides - each food was paired with every other food and offered on the left and right plate in separate trials. The food pairs were presented in a pseudorandom order such that the same foods were not offered on successive trials. The experimenter would prepare the test foods according to the pre-determined order of presentation and replace the plate as the dog was walked to the start point. Plates were washed thoroughly between dogs.

At the beginning of each trial, the dog would be on a

Apparatus 
each food was presented singly on either the left or right side to familiarise the dog with the procedure. Once a food was selected, operationalised as the dog picking the food up in their mouth and not expelling it, the owner would allow the dog to eat the food. The owner then led the dog in the same direction as the dog's choice (left or right) in a circular motion back to the starting point to await the next trial.

\section{Reinforcer Assessment}

The dogs were required to move from a sitting position down the 'runway' to a point 5-m distant for a sample of either their most, least preferred or staple foods. Owners would hold their dogs in place by the collar then release the dog to move toward the food. The latency from the 'start' to the consumption of food was measured. The owner would then attach a lead and return the dog to the start position. To ensure the reliability of the impact of a dog's demand for an individual food item the dog was given five separate opportunities to obtain each food in an ABCD repeated measures design; $(A=$ most-preferred food for 5 trials, $\mathrm{B}=$ least-preferred food for 5 trials, $\mathrm{C}=$ rabbit (or lamb for Indy) as the staple food for 5 trials, and $D=$ horse as the staple food for 5 trials).

\section{RESULTS}

All food types were selected at least once by all dogs in the paired stimulus preference assessments. Table 2 shows the rank order of preference for each dog and the proportion of trials (out of 20) when each food was chosen across the two sessions. Wilcoxon signs ranks tests revealed no differences between the rank orders of food for the first preference test when rabbit was the staple food, and the second test when horse was the staple food for all of the dogs [Bradley $\mathrm{W}=-0.41, \mathrm{p}=$ 0.684; Indy $\mathrm{W}=-0.27, \mathrm{p}=0.786 ; \mathrm{Max} \mathrm{W}=0.00, \mathrm{p}=1.00$; Miika $\mathrm{W}=0.00, \mathrm{p}=1.00$, Moe $\mathrm{W}=0.00, \mathrm{p}=1.00$; Poppy $\mathrm{W}=-0.41, \mathrm{p}=0.686 ; \operatorname{Rex} \mathrm{W}=-0.11, \mathrm{p}=0.916 ;$ Runty $\mathrm{W}=$ $0.00, p=1.00$; Skye $\mathrm{W}=0.00, \mathrm{p}=1.000]$. Overall, lamb, duck, and tripe featured as the most-preferred food for two each of the nine dogs, with the remaining dogs indicating their most-preferred food was either chicken, rabbit or horse.

\begin{tabular}{ccccccc}
\hline \multicolumn{7}{c}{ Preference order } \\
\hline Dog & $1^{\text {st }}$ & $2^{\text {nd }}$ & $3^{\text {rd }}$ & $4^{\text {th }}$ & $5^{\text {th }}$ & $6^{\text {th }}$ \\
\hline \multirow{2}{*}{ Bradley } & $\mathrm{C}$ & $\mathrm{D}$ & $\mathrm{L}$ & $\mathrm{T}$ & $\mathrm{R}$ & $\mathrm{H}$ \\
& $(0.60)$ & $(0.60)$ & $(0.60)$ & $(0.45)$ & $(0.40)$ & $(0.35)$ \\
Indy & $\mathrm{L}$ & $\mathrm{D}$ & $\mathrm{R}$ & $\mathrm{C}$ & $\mathrm{H}$ & $\mathrm{T}$ \\
& $(0.70)$ & $(0.60)$ & $(0.55)$ & $(0.40)$ & $(0.40)$ & $(0.35)$ \\
Max & $\mathrm{L}$ & $\mathrm{D}$ & $\mathrm{T}$ & $\mathrm{R}$ & $\mathrm{C}$ & $\mathrm{H}$ \\
& $(0.75)$ & $(0.70)$ & $(0.50)$ & $(0.45)$ & $(0.30)$ & $(0.30)$ \\
Miika & $\mathrm{D}$ & $\mathrm{L}$ & $\mathrm{T}$ & $\mathrm{H}$ & $\mathrm{C}$ & $\mathrm{R}$ \\
& $(0.75)$ & $(0.60)$ & $(0.55)$ & $(0.50)$ & $(0.30)$ & $(0.30)$ \\
Moe & $\mathrm{D}$ & $\mathrm{C}$ & $\mathrm{L}$ & $\mathrm{H}$ & $\mathrm{T}$ & $\mathrm{R}$ \\
& $(0.85)$ & $(0.60)$ & $(0.60)$ & $(0.40)$ & $(0.35)$ & $(0.20)$ \\
Poppy & $\mathrm{R}$ & $\mathrm{C}$ & $\mathrm{D}$ & $\mathrm{L}$ & $\mathrm{H}$ & $\mathrm{T}$ \\
& $(0.75)$ & $(0.60)$ & $(0.50)$ & $(0.45)$ & $(0.35)$ & $(0.35)$ \\
Rex & $\mathrm{T}$ & $\mathrm{H}$ & $\mathrm{D}$ & $\mathrm{L}$ & $\mathrm{C}$ & $\mathrm{R}$ \\
& $(0.75)$ & $(0.65)$ & $(0.45)$ & $(0.45)$ & $(0.35)$ & $(0.35)$ \\
Runty & $\mathrm{H}$ & $\mathrm{T}$ & $\mathrm{R}$ & $\mathrm{C}$ & $\mathrm{D}$ & $\mathrm{L}$ \\
& $(0.75)$ & $(0.60)$ & $(0.50)$ & $(0.40)$ & $(0.40)$ & $(0.35)$ \\
& $\mathrm{T}$ & $\mathrm{L}$ & $\mathrm{D}$ & $\mathrm{R}$ & $\mathrm{C}$ & $\mathrm{H}$ \\
Skye & $(0.75)$ & $(0.60)$ & $(0.60)$ & $(0.50)$ & $(0.40)$ & $(0.15)$ \\
\hline
\end{tabular}

Table 2. Relative preference for each food type (C Chicken; D Duck; L Lamb; T Tripe; R Rabbit; H Horse) for each dog summed across two sessions. The proportion of trials when each food was chosen is given in parentheses.

The average proportion of trials when each food was chosen was compared across dogs to assess whether preference was affected by the quality of staple food (Figure 1). The data for Indy was not included in the analysis as she received lamb as a staple food instead of rabbit. Overall duck was preferred in significantly more trials than chicken when rabbit $[Z=-2.3, p=0.050]$ and horse were offered $[Z=-2.17, p=0.038]$. Preference for the each of the staple foods was not significantly higher when that food was available as the staple food; for rabbit $[Z=-1.83, p=0.068]$ and for horse $[Z=-0.99, p=$ 0.322].

The reinforcer assessment required each dog to move 5$\mathrm{m}$ to earn a sample of food. The samples were the mostand least-preferred foods and the staple foods for each dog. As there were five trials per food type, the first trial was omitted in the analysis (Figure 2).

A Friedman statistical analysis revealed significant differences between the average latencies to travel 5-m to obtain either the most- and least-preferred, and the two staple foods $[\chi 2(3)=36.98, p<0.001, W=0.39]$. 
three days before testing. The results indicate a high

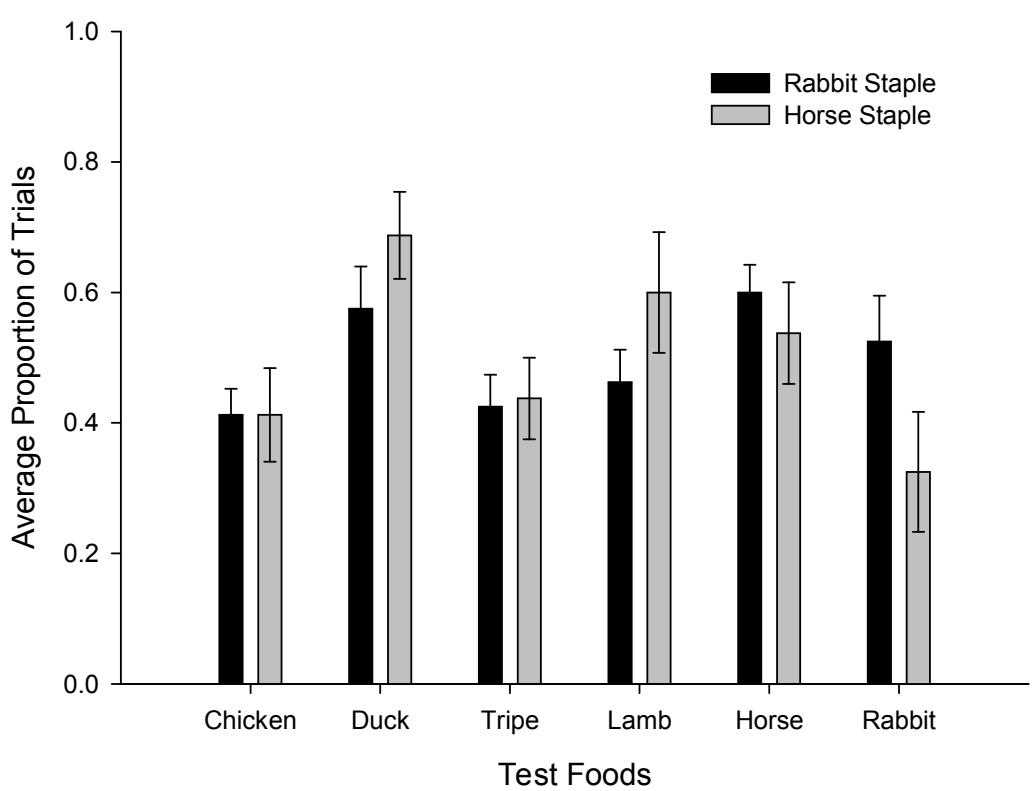

Figure 1. Proportion of trials when each test food was selected by each dog. The darker columns represent the proportion of trials when rabbit was the staple food; the light grey columns represent the proportion of trials when horse was the staple food. The data for Indy was not included in the analysis. Error bars are the standard error of the mean.
Data for one dog (Runty) was omitted from the analysis as their most-preferred food was not tested during the reinforcer assessment. Pairwise comparisons revealed significantly faster average latencies to receive the most-preferred food compared to both staple foods [all $p$ 's $<0.001]$, and the least-preferred food [p $<0.001]$.

Latencies to obtain the least-preferred foods were significantly slower than for the rabbit staple $[p=0.005]$ and horse staple [p $=0.024]$. There were no significant differences in latency to obtain staple foods [ $p=0.270]$. The absence of a difference in latency means that when the dogs are required to expend effort to obtain a reinforcer, they will move faster for a food of higher value compared to their staple diet or least-preferred food.

\section{DISCUSSION}

In the current study, a paired stimulus preference assessment was used to determine a rank order of foods preferred by dogs fed a specialised 'raw' diet and to measure the effect of staple foods on preference. There were two factors of interest, firstly, whether the rank order of preference was stable over time and if the preference for the staple foods was affected by the provision of these foods (as the normal diet) in the degree of idiosyncrasy in preference similar to that identified previously in dogs (e.g., Vicars, et al. 2014) and other species such as possums (Cameron et al. 2013). The data also showed that some dogs would cover a short distance faster to obtain their mostpreferred food compared to a lowly-preferred or staple food similar to previous works where dogs needed to 'move' to gain a reinforcer (e.g., Riemer et al. 2018; Thompson et al. 2016).

To measure the effect of the staple, most- and least preferred foods on behaviour, we used a task combining effort and choice. The dogs were required to cover a 5-m distance to obtain a reinforcer. This method produced significant differences in latencies for five dogs when offered the reinforcer options and provides an 'unconditioned' utility for measuring effort to obtain a reinforcer in shelter, young or minimally trained dogs. The utility of quick and reliable preference assessments is of considerable applied interest. A variety of methods and techniques have been developed that vary in complexity and ease of use. These extend from simple single stimulus presentations that are useful for palatability tests to paired stimulus and multiple stimulus presentations methods that provide rank orders of preference for foods (for examples see Cameron et al. 2013, Fisher et al. 1992 and 
Sumpter et al. 2002).

The reinforcer assessment for each dog consisted of blocks of five trials of the most-, least preferred and the two staple foods, presented in that order to each dog. Latencies were longer latencies in the final trials of the session which one could attribute to an order effect, especially as they were receiving their staple food. The data in Figure 2, however, shows that dogs moved with similar latencies for both staple foods across the penultimate (rabbit staple) and final set (horse staple) of five trials. In future experiments, the order of presentation for the staple, most- and least-preferred foods will be randomized across dogs and repeated sessions. Furthermore, as the task required to obtain the food was not behaviourally different from that of the paired stimulus preference assessment that all dogs had experienced in earlier sessions, the 'novelty' of the task is unlikely to have caused the dogs to move faster to gain the food for any reason other than whether the food was of high- or low-value to the dog. assessment. In the current experiment, the design of the preference assessment combined an effortful behaviour to obtain food, while also choosing competing foods, effectively precluding the need for a reinforcer assessment; as the results of the assessments corroborated the identification and effectiveness of the reinforcers.

The requirement to move down the runway functioned as a fixed ratio schedule of reinforcement and if latency to approach the food was measured concurrently with choice one could simultaneously identify the relative demand of two commodities in dogs. Future research will attempt to determine a reliable and easy to administer preference-assessment methodology that can be used by dog owners to easily and reliably assess their dog's preferred reinforcer. Also, a comparison of different preference assessment methods such as the paired stimulus preference assessment and multiple stimuli without replacement methods (MSWO; DeLeon and Iwata 1996) with the results of a reinforcer assessment. By presenting a dog with an effortful task

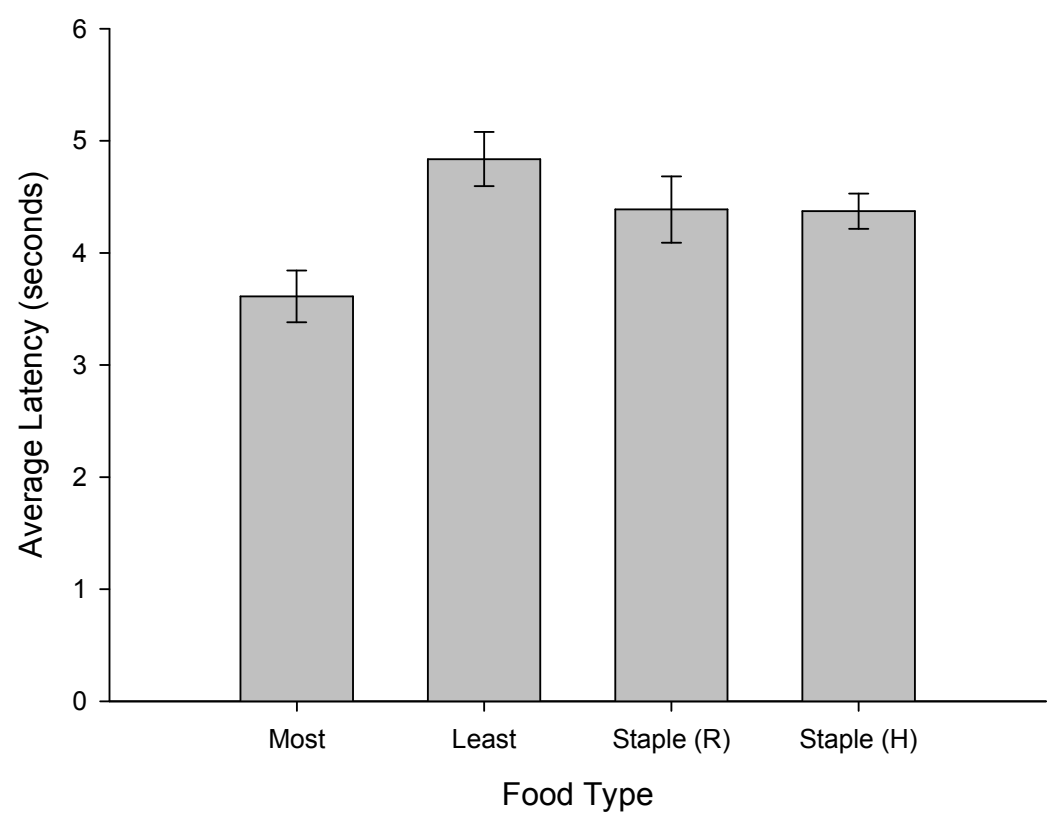

Figure 2. Average latency (seconds) to complete a $5 \mathrm{~m}$ distance across dogs for the most- and least preferred and staple food ( $R$ = Rabbit; $\mathrm{H}=$ Horse). The food types are shown in order of presentation to the dogs with the final four trials used for each block of trials. Error bars are the standard error of the mean.
Use of a runway in previous experiments with dogs have functioned more so as a reinforcer assessment and have measured either latency to approach (Riemer et al. 2018) or interactions with inaccessible food (Thompson et al. 2016). They did not provide different choices for food over trials as one might in a preference that results in a reinforcer of their choice one would predict that an animal would select the foods of highest-value before they are willing to repeat the work required to choose the next most preferred item. Such a technology would hopefully improve the likelihood that chosen rewards would function as reinforcers and 
improve training outcomes.

In conclusion, this study has identified that a high value 'flavour' could be withheld and used as a reinforcer for training dogs on a restricted diet. The present study has demonstrated the utility of simple reinforcer preference assessments with dogs and builds on a previous body of research on humans and animals that attempts to find practical and cost-effective methods for assessing reinforcer preference. Our method was practical and reliable and will be a useful tool for pet owners and behavioural scientists in determining a high-value food for reinforcing animals for the desired behaviour in training and behavioural testing.

\section{ACKNOWLEDGEMENTS}

Portions of these data were also reported at the New Zealand Companion Animal Council conference in Auckland, New Zealand 2018. The authors would like to thank the dog owners and dogs for participating in the experiment. This research was conducted following the relevant ethics guidelines and approved by the Animal Ethics Committee at the University of Auckland where this research was conducted. The first author can be contacted at Unitec Institute of Technology; kcameron@unitec.ac.nz.

\section{REFERENCES}

Ackerman, N. 2016. Evidence surrounding the feeding of natural/raw diets to dogs and cats. The Veterinary Nurse 7: 5-8.

Bentosela, M., Jakovcevic, A., Elgier, A. M., Mustaca, A. E., and Papini, M. R. 2009. Incentive contrast in domestic dogs (Canis familiaris). Journal of Comparative Psychology 123: 125-130.

Bizo, L. A., and Killeen, P. R. 1997. Models of ratio schedule performance. Journal of Experimental Psychology: Animal Behavior Processes 23: 351-367.

Blackwell, E. J., Twells, C., Seawright, A., and Casey, R. A. 2008. The relationship between training methods and the occurrence of behavior problems, as reported by owners, in a population of domestic dogs. Journal of
Veterinary Behavior: Clinical Applications and Research 3: 207-217.

Bradshaw, J. W. S. 2006. The evolutionary basis for the feeding behavior of domestic dogs. The WALTHAM International Nutritional Sciences Symposia 136: 19271931.

Cameron, K. E., Bizo, L. A., and Starkey, N. J. 2013. Food preferences of the Brushtail Possum (Trichosurus vulpecula). International Journal of Comparative Psychology 26: 324-336.

Cameron, K. E., Bizo, L. A., and Starkey, N. J. 2015. Assessment of demand for food under concurrent PR and FR schedules in the brushtail possum (Trichosurus vulpecula). International Journal of Comparative Psychology 28: 1-19.

Cameron, K. E., Clarke, K. H., Bizo, L. A., and Starkey, N. J. 2016. Concurrent progressive-ratio and fixed-ratio schedule performance under geometric and arithmetic progressions by brushtail possums. Behavioural Processes 126: 94-100.

Clay, A. W., Bloomsmith, M. A., Marr, M. J., and Maple, T. L. 2009. Systematic investigation of the stability of food preferences in captive orangutans: implications for positive reinforcement training. Journal of Applied Animal Welfare Science 12: 306-313.

Collier, G., Hirsch, E., and Hamlin, P. H. 1972. The ecological determinants of reinforcement in the rat. Physiology and Behavior 9: 705-716.

Dawkins, M. S. 1988. Behavioural deprivation: A central problem in animal welfare. Applied Animal Behaviour Science 20: 209-225.

Dawkins, M. S. 2004). Using behaviour to assess animal welfare. Animal Welfare 13: 3-7.

de Jong, I. C., Wolthuis-Fillerup, M., and van Reenen, C. G. 2007. Strength of preference for dustbathing and foraging substrates in laying hens. Applied Animal Behaviour Science 104: 24-36. 
Deldalle, S., and Gaunet, F. 2014. Effects of 2 training methods on stress-related behaviors of the dog (Canis familiaris) and on the dog-owner relationship. Journal of Veterinary Behavior: Clinical Applications and Research 9: 58-65.

DeLeon, I. G., and Iwata, B. A. 1996. Evaluation of a multiple-stimulus presentation format for assessing reinforcer preferences. Journal of Applied Behavior Analysis 29: 519-533.

Elia, J. B., Erb, H. N., and Houpt, K. A. 2010. Motivation for hay: Effects of a pelleted diet on behavior and physiology of horses. Physiology and Behavior 101: 6237 .

Ferrell, F. 1984. Effects of restricted dietary flavor experience before weaning on post-weaning food preference in puppies. Neuroscience and Biobehavioral Reviews 8: 191-198.

Fisher, W. W., Piazza, C. C., Bowman, L. G., Hagopian, L. P., Owens, J. C., and Slevin, I. 1992. A comparison of two approaches for identifying reinforcers for persons with severe and profound disabilities. Journal of Applied Behavior Analysis 25: 491-498.

Foster, T. M., Sumpter, C. E., Temple, W., Flevill, A., and Poling, A. 2009. Demand equations for qualitatively different foods under fixed-ratio schedules: A comparison of three data conversions. Journal of the Experimental Analysis of Behavior 92: 305-326.

Gaalema, D. E., Perdue, B. M., and Kelling, A. S. 2011. Food preference, keeper ratings, and reinforcer effectiveness in exotic animals: The value of systematic testing. Journal of Applied Animal Welfare Science 14: 3341.

Gourmet PetFood Kitchen Limited. 2015. Woofles Natural Raw Pet Food in Auckland. Retrieved from wooflespetfood.co.nz.

Haverbeke, A., Laporte, B., Depiereux, E., Giffroy, J. M., and Diederich, C. 2008. Training methods of military dog handlers and their effects on the team's performances. Applied Animal Behaviour Science 113: 110-122.
Hewson-Hughes, A. K., Hewson-Hughes, V.L. Colyer, A., Miller, A. T., McGrane, S. J., Hall, S. R., and Butterwick, R.F. Simpson, S.J. Raubenheimer, D. 2012. Geometric analysis of macronutrient selection in breeds of the domestic dog, Canis lupus familiaris. Behavioural Ecology 24: 293-304.

Hiby, E. F., Rooney, N. J., and Bradshaw, J. W. S. 2004. Dog training methods: Their use effectiveness and interaction with behaviour and welfare. Animal Welfare 13: 63-69.

Holm, L., Jensen, M. B., Pedersen, L. J., and Ladewig, J. 2008. The importance of a food feedback in rooting materials for pigs measured by double demand curves with and without a common scaling factor. Applied Animal Behaviour Science 111: 68-84.

Hursh, S. R., Madden, G. J., Spiga, R., DeLeon, I. G., and Francisco, M. T. 2013. The Translational Utility of Behavioral Economics: The Experimental Analysis of Consumption and Choice. In G. J. Madden, W. V. Dube, T. D. Hackenberg, G. P. Hanley, and K. A. Lattal (Eds.), APA handbook of behavior analysis, Vol. 2: Translating principles into practice (Vol. 2, pp. 199-224). Washington, DC, US: American Psychological Association.

Januszczak, I. S., Bryant, Z., Tapley, B., Gill, I., Harding, L., and Michaels, C. J. 2016. Is behavioural enrichment always a success? Comparing food presentation strategies in an insectivorous lizard (Plica plica). Applied Animal Behaviour Science 183: 95-103.

Jarmolowicz, D. P., and Lattal, K. A. 2010. On distinguishing progressive increasing response requirements for reinforcement. The Behavior Analyst 33: 119-125.

Leonardi, R. J., Vick, S. J., and Dufour, V. 2012. Waiting for more: The performance of domestic dogs (Canis familiaris) on exchange tasks. Animal Cognition 15: 107120 .

McGuire, K., Bizo, L. A., McBride, A., and Kocek, T. B. (2018). Discrimination of food amounts by the domestic $\operatorname{dog}$ (Canis familiaris). International Journal of Comparative Psychology, 31. 
Payne, E., Bennett, P. C., and McGreevy, P. D. 2015. Current perspectives on attachment and bonding in the dog-human dyad. Psychology Research and Behavior Management 8: 71-79.

Phillips, C. J., Pines, M. K., and Muller, T. 2012. The avoidance of ammonia by sheep. Journal of Veterinary Behavior: Clinical Applications and Research 7: 43-48.

Rashotte, M. E., Foster, D. F., and Austin, T. 1984. Twopan and operant lever-press tests of dogs' preference for various foods. Neuroscience and Biobehavioral Reviews 8: 231-237.

Riemer, S., Ellis, S. L., Thompson, H., and Burman, O. H. 2018. Reinforcer effectiveness in dogs-The influence of quantity and quality. Applied Animal Behaviour Science 206: 87-93.

Seaman, S. C., Waran, N. K., Mason, G., and D'Eath, R. B. 2008. Animal economics: Assessing the motivation of female laboratory rabbits to reach a platform, social contact and food. Animal Behaviour 75: 31-42.

Sumpter, C. E., Foster, T. M., and Temple, W. 2002. Assessing animals' preferences: Concurrent schedules of reinforcement. International Journal of Comparative Psychology 15: 107-126.
Thompson, H., Riemer, S., Ellis, S., and Burman, O. 2016. Behaviour directed towards inaccessible food predicts consumption - a novel food preference test. Animal Cognition 178: 111-117.

Thompson, L. 2016. Raw Essentials FAQ. Retrieved from http://www.rawessentials.co.nz/site/webpages/general/ gastric-acidity

Vicars, S. M., Miguel, C. F., and Sobie, J. L. 2014. Assessing preference and reinforcer effectiveness in dogs. Behavioural Processes 103: 75-83.

Vitale Shreve, K. R., Mehrkam, L. R., and Udell, M. A. R. 2017. Social interaction, food, scent or toys? A formal assessment of domestic pet and shelter cat (Felis silvestris catus) preferences. Behavioural Processes, 141: 322-328.

Vondran, J. C. 2013. A Two Pan Feeding Trial with Companion Dogs: Considerations for Future Testing. Unpublished master's thesis, Kansas State University, Kansas, USA.

\section{@creative}

This paper has been published by

Pet Behaviour Science

under a Creative Commons license

4.0 Non-comercial - Share Alike - Attribution

As an open access journal, it is free of charges for both authors and readers

www.petbehaviourscience.org 